When I had the McLean tonometer I was unfortunately so busy fitting up and moving into the clinic of our large new hospital, that I only obtained, and that mainly by the work of my assistant, a few comparative measurements. These are printed in Table XIV. The values can hardly be compared for they lie differently on the scale, but the instrument does not appear to offer any real improvement as regards reliability of measurement. The McLean tonometer is a Schiötz tonometer partly turned upside down, and as it is similar to the older instrument both in principle and in build it should measure as well, but nothing has been added which could lead us to expect it to measure better.

The aim of all tonometer workers. should be to use instruments giving values which may be compared, and to agree on the principles on which such work such be based. A tonometer should be like a thermometer (Elliot), inasmuch as when applied to a test apparatus it should give invariable results.

In conclusion, I beg to express my gratitude to Mr. Priestley Smith for his exposition of the Schiötz tonometer, both in his work "On Tonometric Values," and in his letter replying to Col. Elliot's statements. I fully, agree with his conclusion that "It is not proved, and it is not likely that the instrument errs to the extent that McLean's experiments suggest."

\title{
PRACTICAL SYMPATHY FOR THE BLINDED
}

\section{BY}

\section{Captain Francis P. Peirson-Webber.}

\section{True Appreciation}

I write as a blinded man, to help the ophthalmic surgeon to have a nice appreciation of the situation from a blinded point of view, so that advice may be given with such practical sympathy that the natural despondency, which falls so heavily at the outset of blindness, may be brightened by helpful recommendations, and introductions, given with quiet assurance that carries conviction in such a manner as to create hope, desire, and determination to make the most of life, despite the handicap, which exists.

\section{Lectures in Practical Sympathy}

It would be well if the Ophthalmological Society could arrange a course of lectures in Practical Sympathy, to be given throughout the year, so that the sighted friends and sympathisers of the blinded may acquire just that nice knowledge of daily difficulties which so often occur through their ignorance of the true situation. If a register could be compiled of nurses, companions, tutors, and 
honorary friends so trained, the sympathetic difficulties of the ophthalmic surgeon would at once be lightened, and it would be the first step towards immediate happiness and peace of mind, which alone can meet the situation, towards success.

\section{Patients}

It will be seen at a glance that such a systematic arrangement will meet the requirements of all sorts of patients of either sex and all ages. In the case of children, the ophthalmic surgeon will be able to help them most through their parents, who must be firmly impressed with the necessity of so arranging nursery life that the child may enjoy happy independence, and quicken the intelligence, by the manner in which it is trained to appreciate the importance of sequential deductions, this being the key-note to happy independence in all things. It is of little avail to send a child to a College for the Blinded, or an up-to-date Institute, if its home-life is to be handicapped by inconsiderate difficulties that true appreciation would readily remove. In the case of older patients the initial advice must be precisely the same, and there is no apparent reason why, in many cases, the ophthalmic surgeon should not be able to arrange for one of his family or staff to be so trained, while at all times it is of the first importance that he himself should have a personal acquaintance with the system which is employed, and with those who may be registered as qualified to teach it.

\section{The Situation}

When anyone first loses sight the situation is so overwhelming, so dark, so apparently hopeless, that there is a natural tendency to discredit the practical possibilities of regaining a happy independence. Such a state of mind appears so to act upon the nervous system as to make many sufferers morbid, super-sensitive, and irritable. Consequently, it is all important that there should be no aggravation of such symptoms. Never force the situation. Encourage healthy exercise, humouring the description to meet the convenience of the occasion and the temperament of the individual.

\section{Exercise}

Nothing will bring greater peace of mind, and strength of thought, than the healthy exercise of brain and body. What more invigorating than a good swinging walk with a cheery friend of descriptive powers, so that one sees through the brain old familiar sights, thus enabling anyone to have a sequential train of thought, which not only conveys a rapid appreciation of precise locality, but also revives happy recollections of a good day's sport, or a keen desire to know the nature of crops, the condition of the river, or the 
strength of the hedges, as well as their verdant beauty. For the brain craves for colour pictures, and assimilates them readily with vivid alacrity. Hack riding, tandem cycling, and team driving can all be described, if wished, but these are not for the novice. But log sawing, club swinging, dumb-bells, Sandow and Müller exercises are within the capacity of all, and usually should be associated with a cold tub to follow, or better still, a swim. Many would be surprised what a relief to the mind will be found in knitting, netting, crochet, bead stringing, and the learning of Braille, the almost universal system of raised caligraphy for the blinded.

\section{Friendship}

If it is wished to offer the hand of true friendship to the newly blinded, a letter of quiet sympathy expressing a desire to meet, and arranging a day to call, will be appreciated and looked forward to with keen desire, whereas a sudden greeting in a public place, or by chance elsewhere, will often confuse and aggravate, more especially if the greeting is one of cheery chaff that claims acquaintance off-hand, and says "Who is it ?" For the mind is not yet trained to adapt itself to such rapid deduction, and failure to be normal in public, or to recognize readily the voice of an old friend, is far more difficult than might be imagined, while it hits the very seat of trouble, and conveys a feeling of helpless incapacity which is at once lost as soon as proper training and happy arrangements are made to avert such incidents.

\section{Useful Knowledge}

The ophthalmic surgeon will do well to have a useful knowledge of the blinded world, by personal acquaintance with the leading men who do so much to help forward progressive possibilities, and of such Institutes and Societies as are prinicipally responsible for the training and education of the blinded. Of these the National Institute for the Blind, 226, Great Portland Street, London, will ever be found ready to help in a most practical manner with advice, and introductions suited to the occasion. Probably there are few sighted men who have so great a popularity, and command so thoroughly the confidence and appreciation of the blinded, as Mr. Stainsby, the Secretary-General, for his knowledge is supreme, and his sympathy so genuine and practical. At this great Institute the Braille Printing Works are a special feature, while an Information and Employment Bureau also forms part of its many vocations. In the shop department, many appliances helpful to the blinded may be purchased, including the Stainsby-Wayne Braille Writing Machine, Mr. Stainsby having given his great invention as a gift to the blinded, his name 
alone being retained in memory of such generosity. Braille Instruction Books, Braille Pocket-Writers, Braille Magazines, Roman-Type Writing Frames, and a host of other things of practical interest must be seen to be fully appreciated.

The National Library for the Blind, 18, Tufton Street, Westminster, London (for ever to be associated with the life-work of the late Miss Austin and the helpful munificence of the Carnegie Trust Fund), has some 70,000 volumes in Braille type for distribution throughout the Kingdom, while other great libraries at Oxford and Cambridge still further add to the wonderful collection of books inscribed in Braille for the blinded, and may all be found in a Universal Catalogue of United Braille Libraries. Musical recitals and Shakespearean readings take place at the National Library for the Blind, while there is a reading room, with current literature in magazine and periodical form for the use of visitors who may not be subscribers to all the journals in Braille. Henshaw's Asylum for the Blind, Manchester, and the General Institute for the Blinded, Edgbaston, Birmingham, are the two principal centres of information and education for the Midlands, while Wavertree School for the Blind, Liverpool, is perhaps one of the most progressive schools for blinded children, having a strong section of blinded girl guides and boy scouts; Bradford Institute for the Blinded, Yorkshire, has some noted workshops, while the Royal Normal College for the Blinded, Upper Norwood, London, is noted for its musical training course, though other institutes are also quite remarkable in this direction.

But perhaps the most remarkable of all organizations for training the blinded may be found at St. Dunstan's, Regent's Park, London, the well-known hostel for blinded soldiers and sailors. Thanks to the resourcefulness, generosity, untiring energy, and remarkable business capacity of Sir Arthur Pearson, Bart., G.B.E., there is a ready and comprehensive training for all who may have been blinded in the great war, while an after-care system keeps trained men from drifting to failure for lack of a word of advice and help of the right sort at the right moment.

\section{Practical Work for the Blinded}

As soon as a blinded man has gained confidence in himself, the ophthalmic surgeon will do well to advise some more serious work than knitting, or netting, that may have been given at the outset, to encourage peace of mind. Most blinded men will at first resent the necessity of learning Braille, but it is only a fool who does not overcome this natural sentiment, for the delight of reading to oneself cannot be over estimated; besides, it takes many a difficult hour off the hands of our friends, for it is not altogether an easy matter to read happily to the blinded, who at times are very. 
captious critics. Although there are other types for touch-reading, such as "Moon" and "American Point," Braille is now universally taught.

After learning to read and write Braille, it is well to learn to write Roman-Type with a Remington Type-Machine. Nor is it so difficult as might at first be supposed, while it probably keeps one in touch with the sighted world, even more than is possible in any other way. Thanks to the generosity of the Remington TypeWriter Company, The National Institution for the Blind can arrange for a blind man to purchase his type machine at a considerably reduced price, while a Braille Shorthand Machine is also to be had, that will permit a man to take up clerical work of the greatest interest and value. In nearly all cases, the best advice is to encourage a man blinded in middle life, to continue with his old occupation, and usually this is found to be quite possible, for there are few trades that have not been successfully mastered. Blinded politicians, poets, journalists, and naturalists include the poet Milton, the politician Professor Fawcett, and M. Francois Huber, the great naturalist, who originated the observation hive for bees; while we still have with us a great journalist in Sir Arthur Pearson, successful horticulturist in Mrs. Adolphus Duncombe and Captain Towse, V.C., as well as poultry farmers, coal merchants, tea merchants, lawyers, beneficed clergymen, tutors, and many other busy workers in numerous vocations, who can always be referred to for advice, if approached the right way. At most Institution Work shops the usual trades are basket making, carpentry, shoe repairing, brush and mat making, while in some cases these trades are also worked at home, in combination with poultry keeping and gardening.

\section{Play for the Blinded}

But if the mind is to be successful at work, then it is all important that it should have relaxation and healthy change of thought, intimately associated with vigorous exercise that will stimulate the system and keep a man fit. Now the secret of acquiring pro-. ficiency in all matters of happy independence, is to acquire a habit of making rapid sequential deductions, and it will then be found that it is possible to do most things, even if one may not do them quite so rapidly as the sighted. All kinds of angling and fishing may be enjoyed by the blinded, while rowing, yacht sailing, riding, cycling, skating, rinking, dancing, and even team driving, can all be practised by a blinded man of the right sort with a happy knowledge of his subject. So far as indoor games and pursuits are concerned, we have reading, writing, cards, including whist and bridge. Chess, dominoes, draughts, the pleasure and practise of music, including every kind of instrument, as well as vocal proficiency, so as to be 
able to accept engagements at concerts and entertainments. Knitting, netting, fine needlework, household duties, such as cooking, washingup, bed-making, etc., all such occupations are a healthy change to a large number of blinded persons, who may be making some other subject their special walk in life.

\section{Success for the Blinded}

If a full success is to be achieved by any blinded man, then he must be very careful to guard against a false conceit, for the kindly sympathy of the general public may be apt to upset the true position, unless a man has seen something of the world, and can steady himself to appreciate the truth. Healthy independence is the keynote to success, intimately associated with ability, perseverance, environment, and a love for the work. Always encourage a man to take up the life for which he has the greatest inclination and place him in a position to be able easily to make good use of his powers.

May it be hoped that this short paper will to some extent help the ophthalmic surgeon to get in touch with a practical power to help his patients to happy self-reliance. Should, however, further information be required, then it is hoped that all who may wish to do so, will write to Captain Peirson-Webber, of Ettington Manor, Stratford-on-Avon.

\section{DISEASES OF THE OPTIC NERVE AS MET WITH IN THE GOVERNMENT OPHTHALMIC HOSPITAL, MADRAS}

BY

H. KiRKPATRICK,

MAJOR I.M.S.; SUPERINTENDENT, GOVERNMENT OPHTHALMIC HOSPITAL, MADRAS.

FOR the past few years it has been the custom at the Madras Ophthalmic Hospital to take notes of a routine character on most of the cases of fundus disease which come for treatment.

The first thing which must strike an ophthalmic surgeon new to the country is the very high proportion of optic nerve desease met with, especially atrophic conditions. Such disease represents nearly half the total of all fundus cases seen at this hospital.

The attached table shows that the diseases have been divided into four groups. First, those which are suffering from an active inflammatory condition associated with hyperaemia and swelling; second, those in which the inflammatory stage has passed away 